\title{
Effects of freezing and thawing cycles on the quality of Nile tilapia fillets
}

\author{
Jovana Silva Garbelini ZUANAZZI ${ }^{1 \star}$, Elenice Souza dos Reis GOES ${ }^{2}$ (D), Fernanda Losi Alves de ALMEIDA ${ }^{3}$, \\ Marcio Douglas GOES ${ }^{4}$, Jorge Antônio Ferreira de LARA ${ }^{5}$, Ricardo Pereira RIBEIRO ${ }^{6}$
}

\begin{abstract}
The aim of this investigation was to evaluate the impact of multiple freezing and thawing cycles on the physicochemical properties of Nile tilapia fillets. For this purpose, 72 fresh Nile tilapia fillets were packed and stored in a freezer at $-18{ }^{\circ} \mathrm{C}$. The frozen samples were submitted to five freeze-thaw cycles; in each cycle, the freezer was switched off during 14 hours. The consecutive freeze-thaw cycles resulted in a fillet's total weight loss of $9.48 \%$, with a quadratic regression $(\mathrm{P}<0.0001)$ for thaw loss, with a greater loss percentage in cycle $3(2.68 \%)$. pH values differed between the cycles $(\mathrm{P}<0.0001)$, being observed an increment in this parameter only from cycle 4 . The lipid oxidation remained constant in cycles $1,2,4$ and 5 , however in cycle 3 the lowest value $(\mathrm{P}<0.0002)$ was observed. The luminosity, and intensity of the red and yellow colours increased linearly $(\mathrm{P}<0.0001)$ as the cycles increased. Thereby, the tilapia fillets' quality were adversely affected by the freezing cycles. The unfavourable alterations included weight loss, lipid oxidation and elevated $\mathrm{pH}$, as well as the increasingly augmentation of brightness and red and yellow colorations of fillets as the progressive cycles occurred.
\end{abstract}

Keywords: aquaculture; colour; Oreochromis niloticus; lipid oxidation; pH.

Practical Application: Several cycles of freezing and thawing cause harmful changes in the quality of tilapia fillets.

\section{Introduction}

Meat freezing has been employed as conservation strategy for thousands of years, and even today, this process plays a key role in ensuring the safety of products that are marketed worldwide (Leygonie et al., 2012).

Through the freezing process, it is possible to extend fish's shelf life, aggregate commercial value to the product and reach distant markets (Ninan, 2018). Freezing not only slows down the rate of bacterial growth but also the chemical changes responsible for quality deterioration (Ordóñez et al., 2005). The method is quite effective in preserving the sensory and nutritional characteristics of the fish, provided that the freezing, storing and thawing processes are appropriately carried out (Turan et al., 2003; Evangelista, 2008).

The loss of frozen meat quality depends on many factors, such as storage temperature, freeze-thaw rate and temperature fluctuations (Srinivasan et al., 1997). Temperature fluctuations or temperature rise usually occur during transportation, distribution, storage and display in retail (Benjakul \& Bauer, 2000; Hansen et al., 2004).

Temperature fluctuations generated by the freeze-thaw cycle stimulate lipid oxidation and accelerate meat surface discoloration (Hansen et al., 2004; Ali et al., 2015). Furthermore, the freeze-thaw process induces the denaturation of muscle proteins, leading to unfavourable changes in meat texture (Jeong et al., 2011). Thus, despite the efficiency of the freezing in guaranteeing both meat quality and nutritional safety, some issues associated with the freezing and thawing cycles remain a major concern for food industry and consumers (Ali et al., 2015).

Understanding the changes generated by the freezing and thawing of fillets is essential for the fish processing industry, since its major aim is to provide high quality products, with high resale values, that are attractive and pleasing to the consumer public (Renerre, 1990). Therefore, studies focused in unravelling the impact of freeze-thaw cycles on colour stability, $\mathrm{pH}$, and lipid oxidation of tilapia fillets seems to be of general interest. Thus, the aim of the present study was to evaluate the effects of multiple cycles of freezing and thawing on the physicochemical characteristics of Nile tilapia fillets.

\section{Materials and methods}

The experiment was carried out in accordance with the guidelines of the Brazilian College of Animal Experimentation (COBEA) and was duly approved by the Ethics Commission on Animal Use (CEUA) of the State University of Maringa, Brazil (CEUA Protocol number 2378110815, November 2015). 


\subsection{Animals}

The fish were cultivated in net tanks located in the Corvo River, in the Diamante do Norte county, Parana, Brazil (22³9'S; $\left.052^{\circ} 46^{\prime} \mathrm{W}\right)$. The animals with a mean weight of $69.75 \pm 9.92 \mathrm{~g}$ were conditioned at the average density of $117 \mathrm{fish} / \mathrm{m}^{3}$ in mesh net tank with structure in aluminium, $3 / 4$-inch mesh screen; PVC coated galvanized wire, equipped with buoys floats suitable for net tanks, circular feeders and coverage structure of the same material.

During the growing period, fish were fed three times a day with commercial feed containing $32 \%$ of crude protein and $3,500 \mathrm{kcal} / \mathrm{kg}$ of digestible energy. Seventy-two animals (mean weight of $835 \pm 0.085 \mathrm{~g}$ and total length of $36.64 \pm 0.96 \mathrm{~cm}$ ) from the sixth generation of the Genetic Improvement of Nile tilapia Program, GIFT/TILAMAX variety, of the State University of Maringa (UEM) were slaughtered. The fish were fasted for 24 hours prior to the slaughter to empty the digestive tract.

Animals were slaughtered by section of the spinal cord and submitted to the ventral opening of the abdominal cavity, from the urogenital orifice to the bones of the mandible, followed by the careful removal of the viscera to avoid contamination of the meat with faecal material. Next, fish were decapitated, with subsequent skin removal and manual filleting. The whole skinless fillets were packed, conditioned in iceboxes and transported to the Meat Analysis Laboratory of the Brazilian Agricultural Research Corporation (EMBRAPA) Pantanal, located in the city of Corumba-MS, where meat quality analyses were performed.

\subsection{Freeze-thaw cycles}

The tilapia fillets were manually packed in polyethylene bags and stored in a freezer at $-18^{\circ} \mathrm{C}$. The frozen samples were subjected to five freeze-thaw cycles. Cycle 1 analyses were performed on the $2^{\text {nd }}$ day of storage; of cycle 2 , on the $7^{\text {th }}$ day of storage; of cycle 3 , on the $9^{\text {th }}$ day of storage; of cycle 4 , on the $14^{\text {th }}$ day of storage, and finally, of cycle 5 , on the $16^{\text {th }}$ day of storage. In each cycle, the freezer was switched off for 14 hours, after which period the fillets were weighed for assessing weight loss by thawing and subjected to colour, $\mathrm{pH}$ and lipid oxidation analyses.

The cycles were performed as a tentative to simulate the temperature fluctuations that the frozen fillets can pass during its transport and exhibition in the trade, thus mimicking events that commonly occur with the product over the fish marketing chain.

\subsection{Thawing weight loss}

The assessment of the thawing weight loss was performed in the 72 fillets and the result expressed as a percentage, calculated by the weight difference between the frozen and thawed fillets.

\section{$2.4 \mathrm{pH}$ and color analyses}

The $\mathrm{pH}$ was measured in triplicate in the 72 fillets, using a Toledo Mettler portable digital potentiometer (model 1140, Mettler-Toledo, Woburn, MA) with an insert electrode for meat.

The luminosity values $\left(\mathrm{L}^{*}\right)$ were obtained with a colorimeter (MINOLTA model CR-10; Minolta Camera Co., Osaka, Japan) at a $90^{\circ}$ angle at room temperature, where $\mathrm{L}^{*}$ defines the luminosity
$\left(\mathrm{L}^{\star}=0\right.$ black and $\mathrm{L}^{*}=100$ white), $\mathrm{a}^{*}$ defines the intensity of red, and $b^{*}$ the intensity of yellow.

\subsection{Lipid oxidation analysis}

The lipid oxidation analysis was performed by the thiobarbituric acid reactive substances (TBARs) method, being assessed 18 fillets per cycle (portions of the same fillets were analysed in each cycle). Approximately $10 \mathrm{~g}$ of each fillet were mixed with $50 \mathrm{~mL}$ of trichloroacetic acid solution (TCA), composed of $7.5 \%$ TCA, $0.1 \%$ propyl gallate and $0.1 \%$ EDTA, and were next homogenised for 1 minute and filtered. In each test tube $4 \mathrm{~mL}$ of the filtrate were mixed with $1 \mathrm{~mL}$ of $7.5 \%$ TCA solution and $5 \mathrm{~mL}$ of $0.02 \%$ TBA solution. These tubes were covered and heated in a water bath for 40 minutes, cooled in running water and the absorbances read in a spectrophotometer at $538 \mathrm{~nm}$ wavelength. The results were expressed as $\mathrm{mg}$ of malonaldehyde (MDA) per kg of sample (Vyncke, 1970).

\subsection{Statistical analysis}

Data obtained in the $\mathrm{pH}$ and lipid oxidation assays were submitted to analysis of variance (ANOVA), and when significant differences were observed $(\mathrm{P}<0.05)$, Tukey's test was used to compare the cycles. For the data regarding thawing weight loss, luminosity $\left(\mathrm{L}^{*}\right), \mathrm{a}^{*}$ and $\mathrm{b}^{*}$ colour parameters, a regression analysis was performed at $5 \%$ of significance. The analyses were performed by STATISTICA $7.1^{\circledR}$ software (Statsoft Inc., Tulsa, OK, USA).

\section{Results}

The five freeze-thaw cycles resulted in a total weight loss of $9.48 \%$ of the fillets. It was observed a quadratic regression $(\mathrm{P}<0.0001)$ for the thaw loss (Figure 1), with weight loss increasing until cycle 3 , for which the highest loss percentage $(2.68 \%)$ was registered. However, the weight loss values decreased in the following cycles.

The data obtained for in the $\mathrm{pH}$ and lipid oxidation assays are presented in Table 1 . The $\mathrm{pH}$ values differed between the cycles $(\mathrm{P}=0.0001)$, being observed an increment in this parameter only from cycle 4 (from 6.15 in cycle 3 to 6.23 in cycle 4 ).

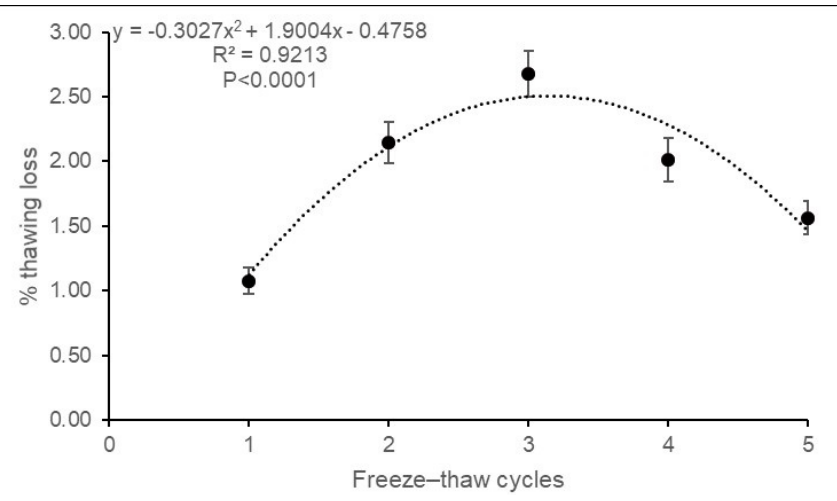

Figure 1. Thawing weight loss of tilapia fillets submitted to different freeze-thaw cycles. Vertical bars indicate the standard error of the mean $(\mathrm{n}=72)$. 
Table 1. Values of $\mathrm{pH}$ and thiobarbituric acid reactive substances (TBARs) concentrations of tilapia fillets submitted to different freeze-thaw cycles.

\begin{tabular}{|c|c|c|c|c|c|c|}
\hline \multirow{2}{*}{ Parameters } & \multicolumn{5}{|c|}{ Freeze-thaw cycles } & \multirow{2}{*}{$\mathrm{P}$ value } \\
\hline & Cycle 1 & Cycle 2 & Cycle 3 & Cycle 4 & Cycle 5 & \\
\hline $\mathrm{pH}$ & $6.14 \pm 0.01 b$ & $6.15 \pm 0.02 b$ & $6.15 \pm 0.01 b$ & $6.23 \pm 0.01 \mathrm{a}$ & $6.19 \pm 0.01 \mathrm{ab}$ & 0.0001 \\
\hline TBARs (mg MA/kg) & $0.59 \pm 0.07 \mathrm{a}$ & $0.68 \pm 0.06 \mathrm{a}$ & $0.33 \pm 0.03 b$ & $0.51 \pm 0.05 \mathrm{ab}$ & $0.48 \pm 0.05 \mathrm{ab}$ & 0.0002 \\
\hline
\end{tabular}

Means followed by different letters indicate difference by the Tukey test. Data expressed as mean \pm standard error. $\mathrm{n}=72$ for $\mathrm{pH}$ an $\mathrm{n}=18$ for TBARs. Mg MA $/ \mathrm{kg}=\mathrm{mg}$ Malonaldehyde $/ \mathrm{kg}$ of fillet.
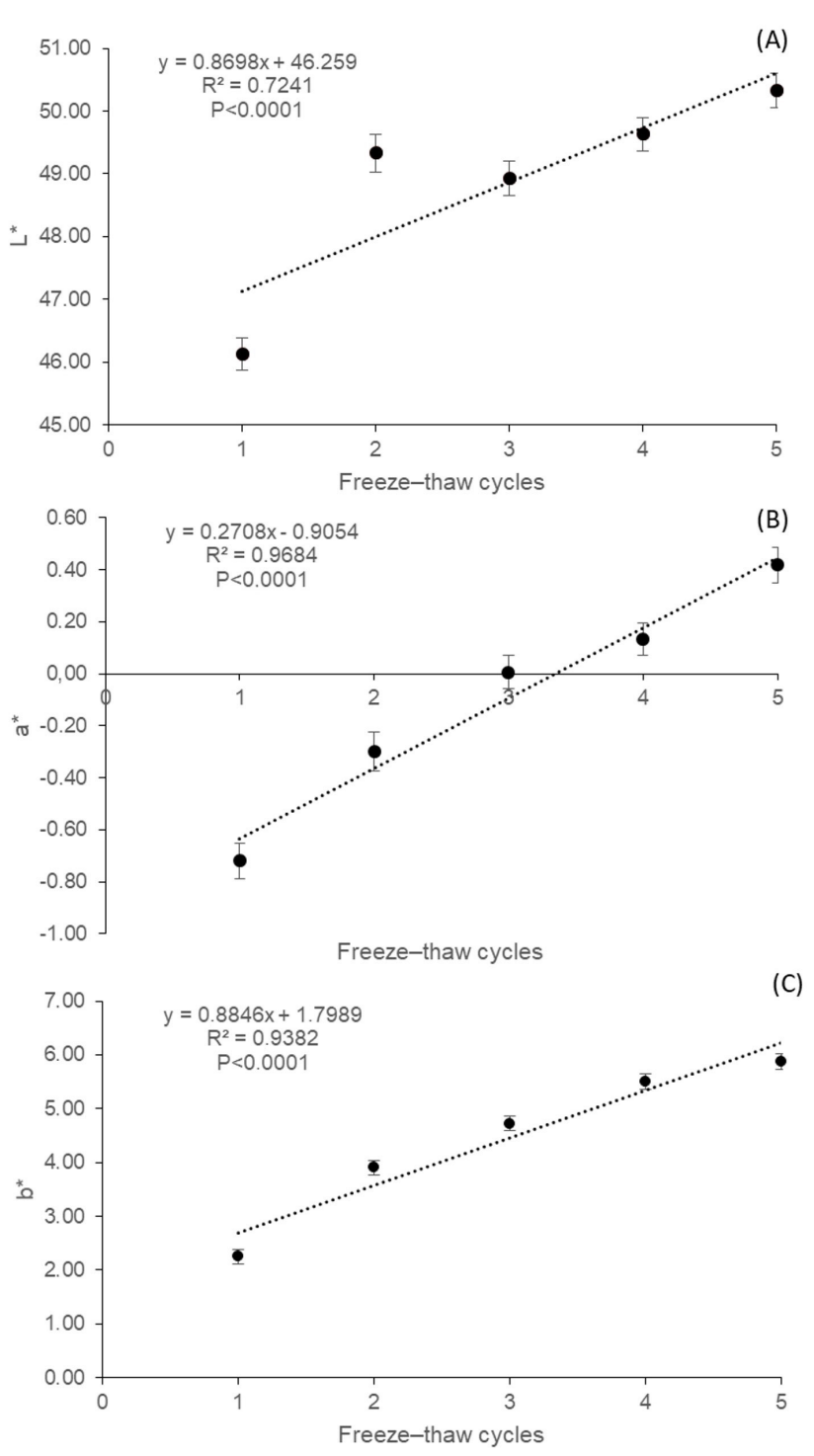

Figure 2. Values of luminosity $L^{\star}(A)$, intensity of red $a^{\star}(B)$ and intensity of yellow $b^{*}(C)$ of tilapia fillets subjected to different freeze-thaw cycles. Vertical bars indicate the standard error of the mean $(n=72)$.

The lipid oxidation analysis revealed constant oxidation in cycles $1,2,4$ and 5 , however in cycle 3 the lowest value of TBARs $(\mathrm{P}=0.0002)$ was observed.

The changes in the fillets colour are displayed in Figure 2. Not only the luminosity $\left(\mathrm{L}^{\star}\right)$, but also the intensities of red $\left(\mathrm{a}^{\star}\right)$ and yellow $\left(\mathrm{b}^{*}\right)$ increased linearly $(\mathrm{P}<0.0001)$ with the number of freeze/thaw cycles performed.

\section{Discussion}

Temperature fluctuations or temperature rise usually occur during transportation, storage or consumption, and repeated freezing/thawing is also common, either in retail or in homes and restaurants (Xia et al., 2010). It is well established that freezing and thawing affect the amount of exudate (thaw loss and/or drip loss) (Leygonie et al., 2012). Water loss affects weight, appearance and sensory properties (Huff-Lonergan \& Lonergan, 2005), and may lead to lower acceptability due to the loss of flavour constituents such as amino acids or nucleotides (Xia et al., 2009). In the present study, the thawing weight loss of tilapia fillets increased until cycle 3 , and decreased in cycles 4 and 5. Normally, weight loss tend to increase linearly with the freeze-thaw cycles, as observed in pig meat (Xia et al., 2009).

This phenomenon occurs due to the loss of the water retention capacity of the muscle, since the repeated formation of ice crystals in the thaw-freeze cycles can cause mechanical damage to the cell membranes, thus impairing its ability to retain water (Srinivasan et al., 1997; Xia et al., 2009).

However, Olsson et al. (2003), when evaluating the water retention capacity behaviour in fish, demonstrated that liquid loss tends to decrease with the storage time (after 8 days of storage at $0{ }^{\circ} \mathrm{C}$, the water retention capacity increased, leading to the decrease in liquid loss of halibut fillets). A similar behaviour was observed for the herein studied tilapia fillets, as from cycle 3 (performed on the $8^{\text {th }}$ day of storage), the liquid loss also decreased. It is likely that the increase in proteolytic activities leads to further protein degradation, including proteoglycan nuclear protein, which contribute to the increase of water retention capacity (Olsson et al., 2003). Liu et al. (2010) found the same tendency when analysing tilapia fillets stored at $0{ }^{\circ} \mathrm{C}$, once fillets' water retention capacity suffered an initial reduce and then increased throughout the storage time.

On the other hand, post-mortem water loss in meat is unavoidable due to the decrease in $\mathrm{pH}$ (closer to the proteins isoelectric $\mathrm{pH}$ ), loss of adenosine triphosphate (ATP) and myofibrils shrinkage caused by rigor mortis (Huff-Lonergan \& Lonergan, 2005). Thus, thawing losses may also be related to the $\mathrm{pH}$ changes of tilapia fillets. Up to cycle 3, the fillets $\mathrm{pH}$ values stayed low. This probably happened because the meat water loss promoted an increase in solutes concentration, resulting in a $\mathrm{pH}$ decrease (Leygonie et al., 2012). At cycles 4 and 5, when thawing losses diminished, $\mathrm{pH}$ values rised. The $\mathrm{pH}$ increase verified from cycle 4 may be related to the formation of alkali compounds in the fillets, which were accumulated through autolytic activities or microbial metabolism (Pons-Sánchez-Cascado et al., 2006). This increase in pH as storage time was also observed for matrinxã (Brycon cephalus) when stored on ice (Batista et al., 2004). 
The successive freeze-thaw cycles resulted in constant lipid oxidation of tilapia fillets, except for cycle 3 that presented the lower oxidation level. Such result seems to be related to the higher thawing loss observed in this cycle. Lipid oxidation is a major problem in frozen fish, as both freshwater and saltwater fish present significant levels of polyunsaturated fatty acids (Benjakul \& Bauer, 2000). In addition, evidence suggest that lipid oxidation occurs mainly at the cell membrane level and not in the triglyceride fraction, which is why lipid oxidation has been reported in lean and fat meats (Thanonkaew et al., 2006; Leygonie et al., 2012). The lipid oxidation side products quality is commonly measured using the thiobarbituric acid reactive substances (TBARS) method. These side products produce rancid, greasy and pungent flavours in meat (Leygonie et al., 2012). Benjakul \& Bauer (2000) reported that the freezing and thawing of catfish (Silurus glanis) muscle tissue resulted in accelerated TBARS accumulation, and attributed this finding to the damage in cell membranes provoked by the formation of ice crystals and the subsequent release of pro-oxidant agents, especially heme iron. In chicken breast fillets, the increase of freeze-thaw cycles resulted in higher levels of lipid and protein oxidation, as evidenced by higher levels of malonaldehyde and carbonyl compounds and lower levels of sulfhydryl groups (Ali et al., 2015).

Besides enhancing lipid and protein oxidation, freeze-thaw cycles reduce the colour stability of meat (Ali et al., 2015). In the present study, such cycles caused an increasing raise of luminosity, accompanied by an increment in the intensity of the red and yellow coloration of the tilapia fillets. Colour alterations may occur during storage due to lipid oxidation and pigment degradation processes (Dias et al., 1994). An increase in brightness could also be a result of protein denaturation associated with freeze-thaw cycles (Jeong et al., 2011). Protein denaturation can happen during freezing due to the increase in intracellular ionic strength after the migration of water into the extracellular spaces (Leygonie et al., 2012).

The increment in tilapia filltes' red colour intensity $\left(\mathrm{a}^{*}\right)$ over the freeze-thaw cycles course may be associated with the denaturation of the globin portion of the myoglobin molecule, which leads to increased susceptibility of myoglobin to auto oxidation and subsequent staining changes (Leygonie et al., 2012). On the other hand, the increase in fillets' yellow coloration intensity $\left(b^{*}\right)$ may be related to the lipid oxidation, which induces the formation of yellow fluorescent pigments in the product, as reported by Hamre et al. (2003) for frozen herring fillets.

\section{Conclusion}

The quality of tilapia fillets were adversely impacted by freezing and thawing cycles. The unfavourable alterations included weight loss, lipid oxidation and elevated $\mathrm{pH}$, as well as the increasingly augmentation of brightness and red and yellow colorations of fillets as the progressive cycles occurred.

Therefore, it is essential to avoid temperature fluctuations during freezing, transportation and storage processes, in order to prevent freeze-thaw cycles from negatively affecting the quality of tilapia fillets.

\section{References}

Ali, S., Zhang, W., Rajput, N., Khan, M. A., Li, C. B., \& Zhou, G. H. (2015). Effect of multiple freeze-thaw cycles on the quality of chicken breast meat. Food Chemistry, 173(1), 808-814. http://dx.doi. org/10.1016/j.foodchem.2014.09.095. PMid:25466093.

Batista, G. M., Lessi, E., Kodaira, M., \& Falcão, P. T. (2004). Alterações bioquímicas post-mortem de matrinxã Brycon cephalus (Günther, 1869) procedente da piscicultura, mantido em gelo. Food Science and Technology, 24(4), 573-581. http://dx.doi.org/10.1590/S010120612004000400016.

Benjakul, S., \& Bauer, F. (2000). Physicochemical and enzymatic changes of cod muscle proteins subjected to different freeze-thaw cycles. Journal of the Science of Food and Agriculture, 80(8), 1143-1150. http://dx.doi.org/10.1002/1097-0010(200006)80:8<1143::AIDJSFA610>3.0.CO;2-C.

Dias, J., Nunes, M. L., \& Mendes, R. (1994). Effect of frozen storage on the chemical and physical properties of black and silver scabbardfish. Journal of the Science of Food and Agriculture, 66(3), 327-335. http:// dx.doi.org/10.1002/jsfa.2740660310.

Evangelista, J. (2008). Tecnologia de alimentos (2. ed.). São Paulo: Atheneu.

Hamre, K., Lie, Ø., \& Sandnes, K. (2003). Development of lipid oxidation and flesh colour in frozen stored fillets of Norwegian spring-spawning herring (Clupea harengus L.). Effects of treatment with ascorbic acid. Food Chemistry, 82(3), 447-453. http://dx.doi. org/10.1016/S0308-8146(03)00070-0.

Hansen, E., Juncher, D., Henckel, P., Karlsson, A., Bertelsen, G., \& Skibsted, L. H. (2004). Oxidative stability of chilled pork chops following long term freeze storage. Meat Science, 68(3), 479-484. http://dx.doi.org/10.1016/j.meatsci.2004.05.002. PMid:22062417.

Huff-Lonergan, E., \& Lonergan, S. M. (2005). Mechanisms of waterholding capacity of meat: The role of postmortem biochemical and structural changes. Meat Science, 71(1), 194-204. http://dx.doi. org/10.1016/j.meatsci.2005.04.022. PMid:22064064.

Jeong, J. Y., Kim, G. D., Yang, H. S., \& Joo, S. T. (2011). Effect of freezethaw cycles on physicochemical properties and color stability of beef semimembranosus muscle. Food Research International, 44(10), 3222-3228. http://dx.doi.org/10.1016/j.foodres.2011.08.023.

Leygonie, C., Britz, T. J., \& Hoffman, L. C. (2012). Impact of freezing and thawing on the quality of meat. Meat Science, 91(2), 93-98. http://dx.doi.org/10.1016/j.meatsci.2012.01.013. PMid:22326063.

Liu, S., Fan, W., Zhong, S., Ma, C., Li, P., Zhou, K., Peng, Z., \& Zhu, M. (2010). Quality evaluation of tray-packed tilapia fillets stored at $0{ }^{\circ} \mathrm{C}$ based on sensory, microbiological, biochemical and physical attributes. African Journal of Biotechnology, 9(5), 692-701. http:// dx.doi.org/10.5897/AJB09.1369.

Ninan, G. (2018). Freezing and frozen storage of fish and shellfish products. In Central Institute of Fisheries Technology (Ed.), Trainig manual on seafood value addition (Chap. 5, pp. 27-36). Cochin: ICAR.

Olsson, G. B., Ofstad, R., Lødemel, J. B., \& Olsen, R. L. (2003). Changes in water-holding capacity of halibut muscle during cold storage. Lebensmittel-Wissenschaft + Technologie, 36(8), 771-778. http:// dx.doi.org/10.1016/S0023-6438(03)00098-7.

Ordóñez, J. A., Rodrigues, C. I. M., Álvarez, F. L., Sanz, G. L. M., Minguillón, F. G. G., Perales, H. L., \& Cortecero, S. D. M. (2005). Tecnologia de alimentos: alimentos de origem animal (Vol. 2). Porto Alegre: Artmed.

Pons-Sánchez-Cascado, S., Veciana-Nogués, M. T., Bover-Cid, S., Mariné-Font, A., \& Vidal-Carou, M. C. (2006). Use of volatile and non-volatile amines to evaluate the freshness of anchovies stored in ice. Journal of the Science of Food and Agriculture, 86(5), 699-705. http://dx.doi.org/10.1002/jsfa.2398. 
Renerre, M. T. (1990). Factors involved in the discoloration of beef meat. International Journal of Food Science \& Technology, 25(6), 613-630. http://dx.doi.org/10.1111/j.1365-2621.1990.tb01123.x.

Srinivasan, S., Xiong, Y. L., \& Blanchard, S. P. (1997). Effects of freezing and thawing methods and storage time on thermal properties of freshwater prawns (Macrobrachium rosenbergii). Journal of the Science of Food and Agriculture, 75(1), 37-44. http://dx.doi.org/10.1002/ (SICI)1097-0010(199709)75:1<37::AID-JSFA838>3.0.CO;2-L.

Thanonkaew, A., Benjakul, S., Visessanguan, W., \& Decker, E. A. (2006). The effect of metal ions on lipid oxidation, colour and physicochemical properties of cuttlefish (Sepia pharaonis) subjected to multiple freeze-thaw cycles. Food Chemistry, 95(4), 591-599. http://dx.doi.org/10.1016/j.foodchem.2005.01.040.

Turan, H., Kaya, Y., \& Erkoyuncu, I. (2003). Effects of glazing, packaging and phosphate treatments on drip loss in rainbow trout (Oncorhynchus mykiss W. 1792) during frozen storage. Turkish Journal of Fisheries and Aquatic Sciences, 3(1), 105-109.

Vyncke, W. (1970). Direct determination of the thiobarbituric acid value in trichloroacetic extracts of fish as a measure of oxidative rancidity. Fette-Seinfen Anstrichmittel, 72(12), 1084-1087. http:// dx.doi.org/10.1002/lipi.19700721218.

Xia, X., Kong, B., Liu, Q., \& Liu, J. (2009). Physicochemical change and protein oxidation in porcine longissimus dorsi as influenced by different freeze-thaw cycles. Meat Science, 83(2), 239-245. http:// dx.doi.org/10.1016/j.meatsci.2009.05.003. PMid:20416749.

Xia, X., Kong, B., Xiong, Y., \& Ren, Y. (2010). Decreased gelling and emulsifying properties of myofibrillar protein from repeatedly frozenthawed porcine longissimus muscle are due to protein denaturation and susceptibility to aggregation. Meat Science, 85(3), 481-486. http://dx.doi.org/10.1016/j.meatsci.2010.02.019. PMid:20416818. 